\title{
A straightforward synthesis of pyrroles from ketones and acetylene: a one-pot version of the Trofimov reaction
}

\author{
Elena Yu. Schmidt, Al'bina I. Mikhaleva," Alexander M. Vasil'tsov, Alexey B. Zaitsev, and \\ Nadezhda V. Zorina
}

A. E. Favorsky Irkutsk Institute of Chemistry, Siberian Branch of the Russian Academy of

Sciences, 1 Favorsky Str., Irkutsk 664033, Russian Federation

E-mail: mikh@irioch.irk.ru

\section{This work is dedicated to Prof. Vladimir I. Minkin on the occasion of his $\mathbf{7 0}^{\text {th }}$ birthday \\ (received 30 Sep 04; accepted 23 Nov 04; published on the web 8 Jan 05)}

\begin{abstract}
Alkyl-, aryl- and hetaryl ketones after a one-pot oximation and treatment with acetylene are converted to 2-mono- and 2,3-disubstituted $\mathrm{NH}$ - and $\mathrm{N}$-vinylpyrroles with alkyl-, aryl- and hetaryl substituents in good yields. The oximation is effected using a $\mathrm{NH}_{2} \mathrm{OH} \cdot \mathrm{HCl}-\mathrm{NaHCO}_{3}$ system at room temperature. The reaction with acetylene is carried out in the presence of the $\mathrm{KOH} / \mathrm{DMSO}$ superbase at $100{ }^{\circ} \mathrm{C}$ under atmospheric pressure.
\end{abstract}

Keywords: Pyrroles, ketones, oximes, acetylene, superbases

\section{Introduction}

Important biological properties of pyrrole derivatives stimulate the incessant search for new and improved methods of the pyrrole nucleus. A progress in the substituted pyrrole synthesis is mostly associated with the modification of classical methods. Typically, a new version of the Paal-Knorr reaction with montmorillonite as a catalyst allows the expediency of the 2,5disubstituted pyrroles synthesis to be considerably improved. ${ }^{1}$ A recent novel synthesis of $N$ substituted pyrroles with rare amino, hydroxy, alkoxy and alkylthio functions at the pyrrole ring is based on the addition of acetylenic or allenic carbanions to isothiocyanates using butyllithium and other superbasic reagents under inert atmosphere at low temperature $\left(-100^{\circ} \mathrm{C}\right){ }^{2}$ A number of modern pyrrole ring constructions employ catalysts composed of expensive platinum group metal derivatives. ${ }^{3,4}$ Some recently developed syntheses, though efficient, appear to be not of general character due to the utilization of exotic starting materials ${ }^{5,6}$ or special structures of the pyrroles formed. ${ }^{3,6,7}$ 


\section{Results and Discussion}

Notwithstanding the advances in the design of complex pyrrole derivatives, there is a lack in practical syntheses of "simple" pyrroles with alkyl, aryl and hetaryl substituents or annelated to common cyclic systems at desired positions, based on readily available starting materials and capable of scaling up to custom batches.

These requirements are fulfilled by the synthesis of pyrroles by the reaction of ketoximes with acetylenes in the MOH/DMSO ( $\mathrm{M}=$ alkali metal) superbasic systems (the Trofimov reaction), ${ }^{8,9}$ which makes diverse 2-substituted, 2,3- and 2,5-disubstituted $\mathrm{NH}$ - and $\mathrm{N}$ vinylpyrroles accessible. In a recent patent, ${ }^{10}$ some other solvents, including $N$ methylpyrrolidone (NMP), and alkali metal alkoxides (along with $\mathrm{MOH}$ ) were claimed to be efficient in this reaction. However, our attempts to reproduce the best example of the patent (reaction of cyclohexanone oxime with acetylene in the $t$-BuOK/NMP system) showed the yield of 4,5,6,7-tetrahydroindole to be $17 \%$, instead of $52 \%$ claimed, thus being in correspondence with the known regularities. ${ }^{9}$

Herein we describe a novel version of the Trofimov reaction, comprising a one-pot transformation of ketones (which are among the most readily available organic compounds) to $\mathrm{NH}$ - and $\mathrm{N}$-vinylpyrroles. The version is devoid of a step of the intermediate ketoxime synthesis, which is always associated with losses of reactants, solvents and time, and in some cases (for example, with water-soluble ketoximes) poses various preparative difficulties. To avoid this cumbersome step, we have attempted a straightforward one-pot ketone-to-pyrrole transformation by the consecutive reaction of a ketone with hydroxylamine and acetylene in the KOH-DMSO system. Such an approach is by far not obvious due to the known oxidative properties of DMSO ${ }^{11}$ which might render the oximation stage impossible.

To investigate the scope and the limitations of this new version of the Trofimov reaction, a number of ketones 1a-h with substituents of diverse nature were tested (results are given in the Table) (Scheme 1).

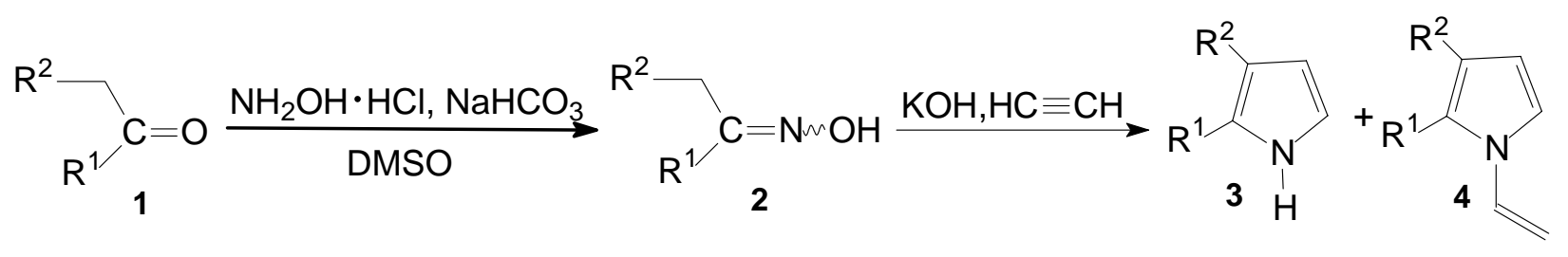

$\mathrm{R}^{1}=\mathrm{Me}, \mathrm{R}^{2}=\mathrm{H}(\mathbf{a}) ; \mathrm{R}^{1}=\mathrm{Et}, \mathrm{R}^{2}=\mathrm{H}(\mathbf{b}) ; \mathrm{R}^{1}=t-\mathrm{Bu}, \mathrm{R}^{2}=\mathrm{H}(\mathbf{c}) ; \mathrm{R}^{1}-\mathrm{R}^{2}=-\left(\mathrm{CH}_{2}\right)_{4^{-}}(\mathbf{d}), \mathrm{R}^{1}=\mathrm{Ph}$, $\mathrm{R}^{2}=\mathrm{H}(\mathbf{e}) ; \mathrm{R}^{1}=2$-Thienyl, $\mathrm{R}^{2}=\mathrm{H}(\mathbf{f}) ; \mathrm{R}^{1}=2$-Furyl, $\mathrm{R}^{2}=\mathrm{H}(\mathbf{g})$

\section{Scheme 1}


It was found that the new one-pot version of the pyrrole synthesis can be successfully extended to ketones of the hydronaphthalene series. For example, from 1-tetralone (1h), 4,5dihydrobenzo $[g]$ indoles $(\mathbf{3 h})$ and $(\mathbf{4 h})$ were readily prepared (Scheme 2$)$.<smiles>C#CC(CO)C1CCCc2ccccc21</smiles>

\section{Scheme 2}

The procedure is carried out under mild conditions $\left(100{ }^{\circ} \mathrm{C}\right)$, its implementation being simple, safe and feasible to any laboratory: acetylene was fed into the reaction mixture under atmospheric pressure.

Utilizing $\mathrm{NaHCO}_{3}$ in this process as a base, instead of alkali (KOH or $\mathrm{NaOH}$ ), prevents possible condensations and methylenation ${ }^{12}$ of starting ketones which are feasible in the $\mathrm{KOH} / \mathrm{DMSO}$ system. Prior to the introduction of $\mathrm{KOH}$ (which, along with DMSO, catalyzes the interaction of oximes with acetylene), ${ }^{8,9}$ the reaction mixture has to be heated $\left(100{ }^{\circ} \mathrm{C}\right)$ and blown out with acetylene for the removal of $\mathrm{CO}_{2}$. 
Table 1. One-pot synthesis of pyrroles from ketones and acetylene $(5 \mathrm{mmol}$ of ketone, $5 \mathrm{mmol}$ of $\mathrm{H}_{2} \mathrm{NOH} \cdot \mathrm{HCl}, 5 \mathrm{mmol}$ of $\mathrm{NaHCO}_{3}, 7.5 \mathrm{mmol}$ of $\mathrm{KOH} \cdot 0.5 \mathrm{H}_{2} \mathrm{O}, 100{ }^{\circ} \mathrm{C}, 5 \mathrm{~h}$, ${ }^{\text {a }}$ atmospheric pressure, acetylene flow rate $15 \mathrm{~cm}^{3} / \mathrm{min}$ )

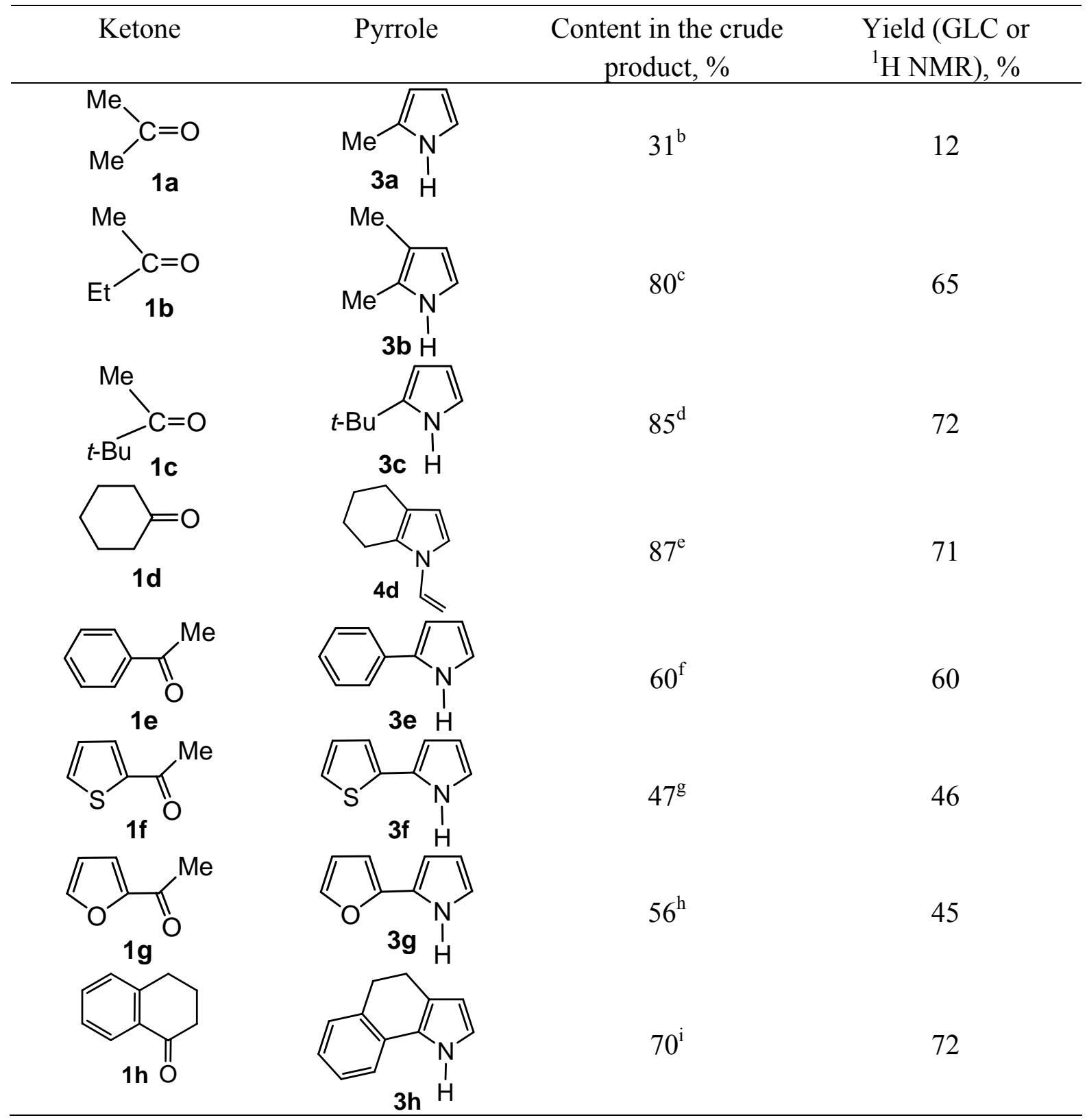

${ }^{\mathrm{a}}$ Acetylene feeding time. ${ }^{\mathrm{b}}$ Other components: ketoxime $\mathbf{2 a}-4 \%, N$-vinylpyrrole $\mathbf{4 a}-38 \%$.

${ }^{\mathrm{c}}$ Other components: $N$-vinylpyrrole $\mathbf{4 b}-20 \%$. ${ }^{\mathrm{d}}$ Other components: $N$-vinylpyrrole $\mathbf{4 c}-15 \%$.

${ }^{\mathrm{e}}$ Other components: pyrrole $\mathbf{3 d}-\mathbf{3} \%{ }^{\mathrm{f}}{ }^{\mathrm{f}}$ Other components: ketoxime $\mathbf{2 e}-30 \%, N$-vinylpyrrole $4 \mathbf{4}-10 \%$. ${ }^{\mathrm{g}}$ Other components: ketoxime $\mathbf{2 f}-47 \%, N$-vinylpyrrole $\mathbf{4 f}-6 \%$. ${ }^{\mathrm{h}}$ Other components: ketone $1 \mathrm{~g}-12 \%$, oxime $\mathbf{2 g}-7 \%, N$-vinylpyrrole $\mathbf{4 g}-25 \%$. ${ }^{\mathrm{i}}$ Other components: $N$-vinylpyrrole $4 \mathbf{h}-30 \%$. 
As seen from Table 1, the conditions chosen (unoptimized) allow the selective preparation of $N$-vinyl-4,5,6,7-tetrahydroindole (4d) (71\% yield). Under the same conditions, 2-phenylpyrrole (3e), 2-thienylpyrrole (3f) and 4,5-dihydrobenzo[g]indole (3h) were also synthesized selectively (60, 46 and 72\% yield, respectively). Acetone (1a) forms 2-methyl- $N H$ - and $N$-vinylpyrroles in low yield, presumably, due to a higher reactivity of the intermediate acetoxime $\mathbf{2 a}$ in side autocondensation processes in the superbasic media. ${ }^{13}$

Analysis of the reaction mixtures by GLC and ${ }^{1} \mathrm{H}$ NMR (Table 1) show that under the conditions studied, conversion of aryl- and heteroarylketoximes in the reaction is incomplete. It is known that to reach their full conversion in the reaction with acetylene [for example, in the

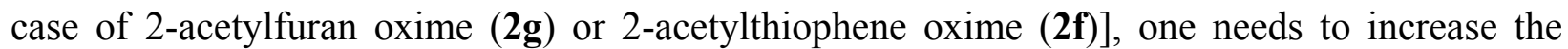
reaction temperature to $130-140{ }^{\circ} \mathrm{C}$ and use longer reaction times $(6-8 \mathrm{~h}) .{ }^{14}$ Obviously, optimization of the conditions (variation of temperature, reaction time, nature and amount of base) for each ketone will allow to improve the yield of target pyrroles and $N$-vinylpyrroles and increase the reaction selectivity for each of them.

In conclusion, a novel version of the Trofimov reaction allowing to accomplish a one-pot synthesis of $\mathrm{NH}$-pyrroles and $\mathrm{N}$-vinylpyrroles directly from ketones and acetylene was developed. Among important advantages of this version are simplicity, technological feasibility (atmospheric pressure of acetylene) and readily available ketones instead of ketoximes. Getting rid of the oximation step and related drawbacks, as well as avoiding inevitable losses occurring during the isolation of the oximes, which lower the total yield of the target pyrroles, increase the preparative efficiency of this method and makes it more attractive to a broad range of researchers involved in pyrrole chemistry.

\section{Experimental Section}

General Procedures. $\mathrm{NH}_{2} \mathrm{OH} \cdot \mathrm{HCl}(5 \mathrm{mmol})$ was dissolved in DMSO $(10 \mathrm{~mL})$ in a 25 -mL flask equipped with a stirrer, and then $\mathrm{NaHCO}_{3}(5 \mathrm{mmol})$ and ketone $(5 \mathrm{mmol})$ were added. The intense evolution of $\mathrm{CO}_{2}$ was observed. The mixture was allowed to stand for 3-4 $\mathrm{h}$ at room temperature until the reaction completion. Then the mixture was heated to $100{ }^{\circ} \mathrm{C}$, and acetylene was fed upon stirring for $0.5 \mathrm{~h}$. After addition of $\mathrm{KOH} \cdot 0.5 \mathrm{H}_{2} \mathrm{O}(7.5 \mathrm{mmol})$, acetylene feeding was continued at the same temperature for $5 \mathrm{~h}$ at a rate of $\sim 15 \mathrm{~cm}^{3} / \mathrm{min}$. Then the mixture was cooled, diluted with water to $\sim 30 \mathrm{~mL}$ and extracted with ether $(5 \times 5 \mathrm{~mL})$. The extracts were washed with water $(3 \times 5 \mathrm{~mL})$ and dried over $\mathrm{K}_{2} \mathrm{CO}_{3}$. After removal of the ether, the residue (crude product) was analyzed by GLC or ${ }^{1} \mathrm{H}$ NMR (Table). For the isolation of the pure pyrroles the column chromatography $\left(\mathrm{Al}_{2} \mathrm{O}_{3}\right)$ was used. First, $N$-vinylpyrrole was eluated with hexane and then, $\mathrm{NH}$-pyrrole was eluted with the system hexane-ether $(3: 1)$. All the characteristics including ${ }^{1} \mathrm{H}$ and ${ }^{13} \mathrm{C}$ NMR-data of the pyrroles 3a-h were corresponded to those of the literature. ${ }^{9}{ }^{1} \mathrm{H}$ and ${ }^{13} \mathrm{C}$ NMR spectra were recorded on a Bruker DPX 400 (400.13 and 100.61 MHz, respectively) 
instrument in $\mathrm{CDCl}_{3}$, using HMDS as an internal standard. IR spectra were recorded on a Bruker IFS 25 instrument.

\section{Acknowledgements}

This work was supported by the Russian Foundation for Basic Research (grants No. 03-03-32472 and No. 2241.2003.3) and the Presidium of the Russian Academy of Sciences (grant No. 10002251/П-25/155-305/200404-072).

\section{References and Footnotes}

1. (a) Samajdar, S.; Becker, F. F.; Banik, B. K. Heterocycles 2001, 55, 1019. (b) Banik, B. K.; Samajdar, S.; Banik, I. J. Org. Chem. 2004, 69, 213.

2. (a) Trofimov, B. A. J. Heterocycl. Chem. 1999, 36, 1469. (b) Brandsma, L. Eur. J. Org. Chem. 2001, 4569.

3. Nishino, F.; Miki, K.; Kato, Y.; Ohe, K.; Uemura, S. Org. Lett. 2003, 5, 2615.

4. (a) Dieter, R. K.; Yu, H. Org. Lett. 2001, 3, 3855. (b) Gabriele, B. T.; Salerno, G.; Fazio, A.; Bossio, M. R. Tetrahedron Lett. 2001, 42, 1339.

5. (a) Bouillon, J.-P.; Hénin, B.; Huot, J.-F.; Portella, C. Eur. J. Org. Chem. 2002, 1556. (b) Fan, X.; Zhang, Y. Tetrahedron Lett. 2002, 43, 1863. (c) Gabbut, C. D.; Hepworth, J. D.; Heron, B. M.; Pugh, S. L. J. Chem. Soc., Perkin Trans 1. 2002, 2799. (d) Cox, M.; Prager, R. H.; Riessen, D. H. ARKIVOC 2001, (vii), 88.

6. Marcotte, F.-A.; Lubell, W. D. Org. Lett. 2002, 4, 2601.

7. Knight, D. W.; Redfern, A. L.; Gilmore, J. J. Chem. Soc., Perkin Trans 1 2002, 622.

8. (a) Gossauer, A. In Methoden der Organischen Chemie. Hetarene I. Teil 1. (Houben-Weyl). Pyrrole. Georg Thieme Verlag: Stuttgart: New York, 1994; p 556. (b) Tedeschi, R. J. In Encyclopedia of Physical Science and Technology; Acetylene. Academic: San Diego, 1992; Vol. 1, 27. (c) Bean, G. P. In The Chemistry of Heterocyclic Compounds Part 1; Pyrroles; Jones, R. A., Ed.; Wiley: New York, 1990; Vol. 48, p 153. (d) Pozharsky, A. F.; Anisimova, V. A.; Tsupak, E. B. Prakticheskie Raboty po Khimii Geterotsiklov (Manual for Heterocyclic Chemistry); Izd. Rostovskogo Universiteta: Rostov, 1988, p 9. (e) Trofimov, B. A. In Adv. Heterocycl. Chem.; Katritzky, A. R., Ed.; Preparation of Pyrroles from Ketoximes and Acetylenes. Academic: San Diego, 1990; Vol. 51, p 177. (f) Trofimov, B. A. In The Chemistry of Heterocyclic Compounds. Part 2; Pyrroles; Jones, R. A., Ed.; Vinylpyrroles. Wiley: New York, 1992; Vol. 48, p 131. (g) Mikhaleva, A. I.; Schmidt, E. Yu. In Selected methods for synthesis and modification of heterocycles; Kartsev, V. G., Ed. Two-step Synthesis of Pyrroles from Ketones and Acetylenes through the Trofimov Reaction. IBS Press: Moscow, 2002; Vol. 1, p 331. 
9. Trofimov, B. A.; Mikhaleva, A. I. N-Vinylpyrroles; Nauka: Novosibirsk, 1984, p 264 (in Russian).

10. Aiscar, B. J. J.; Becker, H.; Henkelmann, J.; Preiss, T. DE 19924041 A 1. 26.05.1999, 30.11.2000; Chem. Abstr. 2000, 134, 4860.

11. Fieser, L.; Fieser, M. Reagents for Organic Synthesis, 1970; Vol.1, p 327 (Russian addition).

12. Trofimov, B. A.; Mikhaleva, A. I.; Petrova, O. V.; Sigalov, M. B. Zh. Org. Khim. 1988, 24, 2095 (in Russian).

13. Mikhaleva, A. I.; Trofimov, B. A.; Vasil'ev, A. N. Zh. Org. Khim. 1979, 15, 602 (in Russian).

14. (a) Trofimov, B. A.; Mikhaleva, A. I.; Polovnikova, R. I.; Korostova, S. E.; Nesterenko, R. N.; Golovanova, N. I.; Voronov, V. K. Khim. Geterotsikl. Soedin. 1981, 1058 (in Russian). (b) Trofimov, B. A.; Mikhaleva, A. I.; Nesterenko, R. N.; Vasil'ev, A. N.; Nakhmanovich, A. S.; Voronkov, M. G. Khim. Geterotsikl. Soedin. 1977, 1136 (in Russian). 